\title{
The orthodontist's profile in Minas Gerais
}

\author{
Luiz Fernando Eto', Valéria Matos Nunes de Andrade²
}

Objective: Due of the growing number of orthodontists and courses in Orthodontics, interest has grown in having a profile of these practitioners in Minas Gerais state (Brazil), showing how do they work in order to promote excellence in orthodontics, showing the most used techniques, the changes in the target public, and other views that impact on the future of the specialty and professional groups.

Methods: Questionnaires were sent to all orthodontists registered with the Regional Council of Dentistry of Minas Gerais (Conselho Regional de Odontologia de Minas Gerais, CRO-MG) until March 30, 2005, consisting of 722 professionals. Questionnaires were sent back by 241 (33\%) professionals.

Conclusions: This study clarified some relevant aspects about the profile of orthodontists in Minas Gerais regarding their individuality, training and the techniques used. The patient base was composed mainly of teenagers (33.75\%) and young adults (27.45\%), with referral predominantly by the patients themselves (46.79\%). Among the most important facts, we can mention the lack of use of some individual protection equipment, with only $37.76 \%$ using all the features of biological safety. Final exams have been requested less frequently than initial records, and findings from the literature review is even more frightening, considering the importance of these records. Looking at the future of the profession, optimistic orthodontists did not exceed half (45\%) of participants.

Keywords: Orthodontics practice. Orthodontics in Minas Gerais state. Orthodontics in Brazil.

${ }^{1}$ Specialist and MSc in Orthodontics, PUC-Minas. Assistant Professor of Orthodontics, University of Itauna. Former-president of the Brazilian Association of Lingual Orthodontics (2006-2010).

${ }^{2}$ Specialist in Orthodontics, Univale. MSc in Orthodontics, São Leopoldo Mandic.

\footnotetext{
How to cite this article: Eto LF, Andrade VMN. The orthodontist's profile in Minas Gerais. Dental Press J Orthod. 2012 May-June;17(3):19.el-9.

Submitted: August 08, 2008 - Revised and accepted: May 11, 2009

» The authors report no commercial, proprietary, or financial interest in the products or companies described in this article.

Contact address: Luiz Fernando Eto

Rua Ceará, 1431 - sala 1302 - Bairro Funcionários - Belo Horizonte / MG

Zip code: 30150-311 - E-mail: ortoeto@globo.com
} 


\section{INTRODUCTION}

Access to the profile of a professional field is of great importance both for those already practicing, as well as for those who will join in the future. Once a profile has been determined, the practitioners will have available valuable information, such as: Where the great demand is located, current professional tendencies, and what changes are occurring within the target public. In addition, enables opinion sharing about the future of the profession.

In the field of Orthodontics, studies are already available showing the profile of the practitioners and the profession. In Brazil, the first research on the profile of orthodontists on a national scale ${ }^{14}$ was performed in 1994.

This present work, however, was motivated by the absence of specific studies on orthodontists in the state of Minas Gerais (MG, Brazil). The present study brings data and conclusions obtained through a questionnaire that sought the following information: professional data, patient demand, philosophy, and perspectives about the profession.

\section{LITERATURE REVIEW}

The United States has carried out most of the statistical surveys aimed at providing a profile of Orthodontics in its various aspects, especially the economic one.

In 1980, 7,500 American Orthodontists were practicing, with an increase of about 230 practitioners per year. ${ }^{4}$ The study found that the average age was 45 years and that men prevalently composed the market (95.5\%). ${ }^{7}$ The requested diagnostic documentation showed heterogeneous distribution: periapical radiographs, $22.5 \%$; bite-wings, $13.6 \%$; panoramic radiography, $91.7 \%$; lateral cephalometrics, $97.8 \%$. At the end of treatment, a considerable reduction in requested documentation was noted: periapical radiographs, 10.5\%; bite-wings, 5.8\%; panoramic radiography, 77.7\%; lateral cephalometrics, $69.3 \% .^{7}$ The cephalometric tracings presented variable preference among Steiner $43.3 \%$, Ricketts $27.4 \%$ and Tweed $27.1 \%$. $^{7}$

In relation to the work philosophy of orthodontists, the literature showed that the practice of orthodontics and orthopedics coexisted. In orthodontics, there was a preference for the fixed and pre-adjusted appliances in comparison to other techniques, such as, standard edgewise (20.0\%), bioprogressive therapy (7.9\%), lingual (1.3\%). In orthopedics, the headgear appliance was indicated more frequently (Kloehn, $36.5 \%$, cervical, $41.5 \%$, and high pull, $26.6 \%$ ), followed by bionator, $23.7 \%$, and bite plane, $23.1 \%$. $^{7}$

Regarding the patients, adult request for treatment was observed as a growing, ${ }^{3,7,15}$ tendency, referred, preferentially, from general dental clinicians $(50 \%)$ or from patients' own initiative $(34.6 \%){ }^{6}$ In respect to the use of technology in the office, only $2 \%$ were computerized, and another $30 \%$ paid specialized companies for this service. ${ }^{5}$

In Brazil, this kind of orthodontic clinical activity survey was carried out in $1992 .{ }^{14}$ The data showed that the average age of practitioners was 42 years. The initial records of patients included initial casts (99.19\%), intraoral photographs (87.71\%), lateral cephalogram (97.58\%) and panoramic radiography (98.31\%) and periapicals $(75.78 \%)$.

In respect to work philosophy, both orthodontics and orthopedics were practiced. Regarding orthodontics, the Edgewise technique was the most prevalent $(52.36 \%)$ in relation to the bioprogressive technique $(35.62 \%)$ or to the continuous arch $(32.62 \%)$; the 0.022-inch slot was the most used (66.5\%). In orthopedic practice, $70.78 \%$ used removable appliances and the bionator was the most prevalently used (75\%).

The daily life of these practitioners, most of them have worked for 16 years in Orthodontics field, consisted of a 40-hour work per week, distributed in four days during the week. On average, treating 16 patients per day, making a total of about 178 patients, referred from colleagues $(44.34 \%)$ or from patients' own initiative $(42 \%)$. In respect to the practitioners, $63.37 \%$ treated ortho-surgical patients and $74.49 \%$ took care of patients with temperomandibular joint (TMJ) disorder. Regarding computer usage in the office, $40 \%$ of the practitioners already had computer services. ${ }^{14}$

In Brazil, the number of orthodontists has grown $37 \%$ in seven years (1993-2001), varying between 1,597 and 3,831 according to data from the Federal Council of Dentistry (Conselho Federal de Odontologia - CFO). In this period, orthodontists consisted $2.2 \%$ of the total of dentists in the country. ${ }^{10}$ Comparing Brazil and the United States, a fact calls attention: despite of having a population equivalent to $40 \%$ of 
that in the United States and $82 \%$ less income, Brazil has almost three times more orthodontics courses $(\mathrm{n}=124,2001){ }^{10}$

The majority of practitioners revealed a pessimistic outlook in regard to the future of the specialty. The main reasons mentioned are: market saturation, unofficial courses, competition with general clinician and insufficient income..$^{10}$

The review of literature showed the absence of more specific studies on the current status of the profession in specific regions in Brazil. In this context, interest has risen in creating a profile of these practitioners in the state of Minas Gerais in order to improve professional practice and achieve excellence. The study sought to show the most utilized techniques used in treatment; the changes in the target public, and the opinions of colleagues relative to the future of the specialty and the role of the regulation institutions.

\section{MATERIALS AND METHODS}

Data collection was done by means of a questionnaire designed by the researchers involved in the study and was comprised of 33 objective questions about the daily work of orthodontists and a descriptive space for suggestions to improve the professional regulation. In addition to the questionnaire, the mailed envelope included a Free and Informed Consent Form that had to be signed by the practitioner participating in the research. The material was then returned by the participants in an enclosed sealed and pre-addressed envelope.

All the material was printed as official document form from the university (UNIVERSIDADE VALE DO RIO DOCE - UNIVALE). The documents were mailed to all orthodontists registered in the Regional Dental Council of Minas Gerais (CRO-MG) up to March 30, 2005. There were 722 active practitioners enrolled, who regularly received mail from the council. The sample consisted of 241 orthodontists who responded and returned the questionnaires.

\section{RESULTS}

From the total of 722 questionnaires mailed, 241 were sent back to the examiners, representing $33.3 \%$ of the initial sample. The collected data were divided as follows.
" Gender: $71.8 \%$ of the orthodontists were male, while 28.2 were female.

»Age: The average age of the orthodontics specialists in Minas Gerais was 39 years, with a minimum age of 27 and a maximum of 82 .

» Marital status: The number of married practitioners represented $75.9 \%$ of the sample; 13.3 were single; 9.5\% responded "other" and $1.2 \%$ did not respond.

» Demographic profile: All the participating orthodontists resided and worked in the state of Minas Gerais, with 11.63\% living around the capital city Belo Horizonte (including cities within 50 kilometers of Belo Horizonte such as: Contagem, $21 \mathrm{~km}$, Nova Lima, 22 km, Betim, 30 km, and São Joaquim de Bicas, $39 \mathrm{~km}$ ) and $88.37 \%$ living in other cities of the State. Practitioners of 74 cities participated spontaneously in the survey.

" Academic degrees: $91 \%$ of those interviewed had formal specialist registration; $24 \%$ had a master's degree and $4.6 \% \mathrm{PhD}$. The State with greatest postgraduate degree practitioners was Minas Gerais with $54.8 \%$, followed by São Paulo, with $29 \%$ (Fig 1).

» Profession: $96.7 \%$ of the practitioners in the sample worked alone and $5.8 \%$ revealed sharing the office with colleagues (Fig 2). Eighty-three percent of the orthodontists declared to work exclusively with orthodontics.

Regarding time in practice, Figure 3 shows that $40 \%$ of the orthodontists had worked for more than 10 years in the specialty; $36.9 \%$ had 5 to 10 years of experience in the field. It was found that $56.4 \%$ of the orthodontist worked an average of 30 to 40 hours per week (Fig 4).

» Patients: $36.1 \%$ of the orthodontists related that they generally treat more than 200 patients (Fig 5). $37.8 \%$ of the professionals related that the average number of patients treated per day was 11 to 20 , as shown in Figure 6.

Adolescents ranging from 10 to 17 years of age made up $33.75 \%$ of the demand for orthodontic treatment, followed by young adults ranging from 17 to 30 years of age $27.45 \%$; followed by children up to 10 years $19.82 \%$ and adults over 30 years representing $18.98 \%$ of the demand.

Patients mainly paid the treatment with own resources, totaling $80.49 \%$, while $19.51 \%$ of the patients came through dental insurance companies. Regarding 


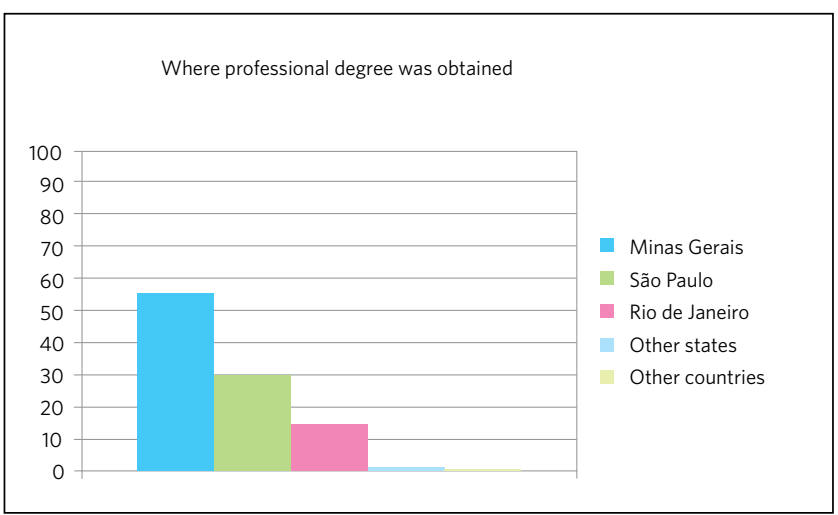

Figure 1 - Distribution of the sample according to the location where professional degree was obtained.

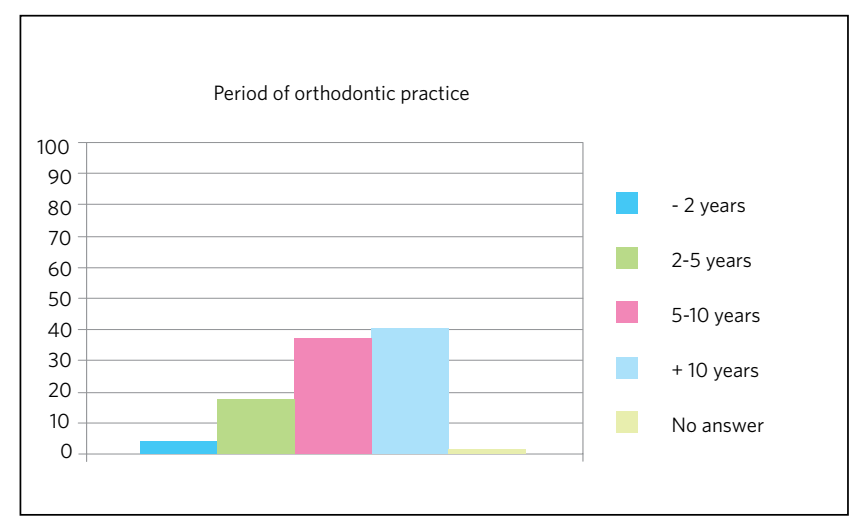

Figure 3 - Distribution of the sample according to the period of orthodontic practice.

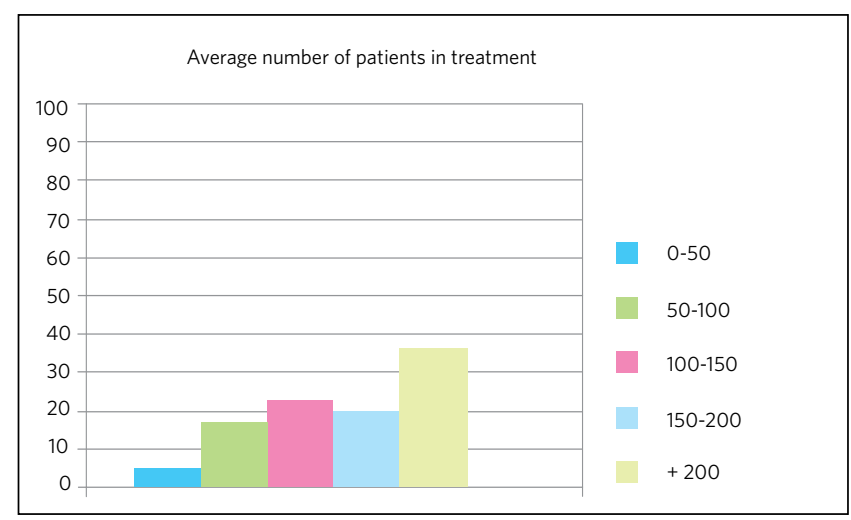

Figure 5 - Distribution of the sample according to the average number of patients in treatment.

reference, $46.79 \%$ of patients came from own initiative and $24.26 \%$ from general clinician referral (Fig 7).

Offices treating more than 15 patients a year with TMD represented $29.5 \%$ of the sample, 6 to 10 patients represented $26.6 \%$ of the sample; up to

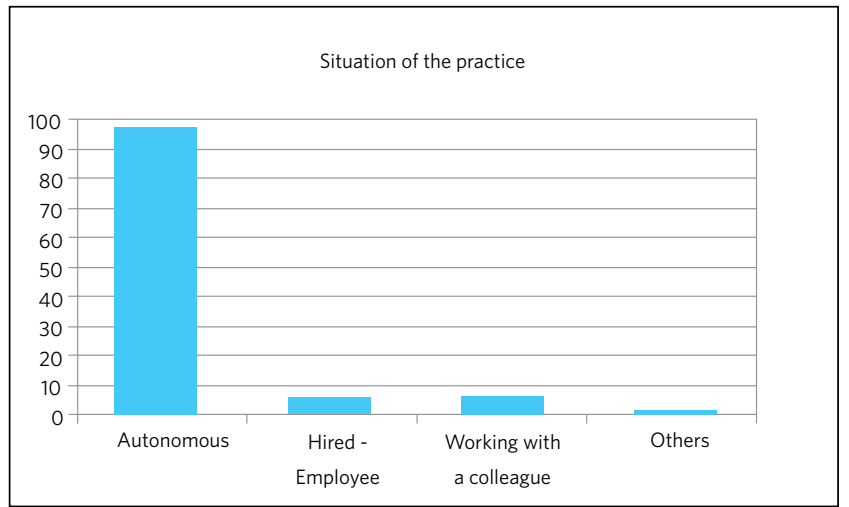

Figure $\mathbf{2}$ - Distribution of the sample according to the situation of the practice.

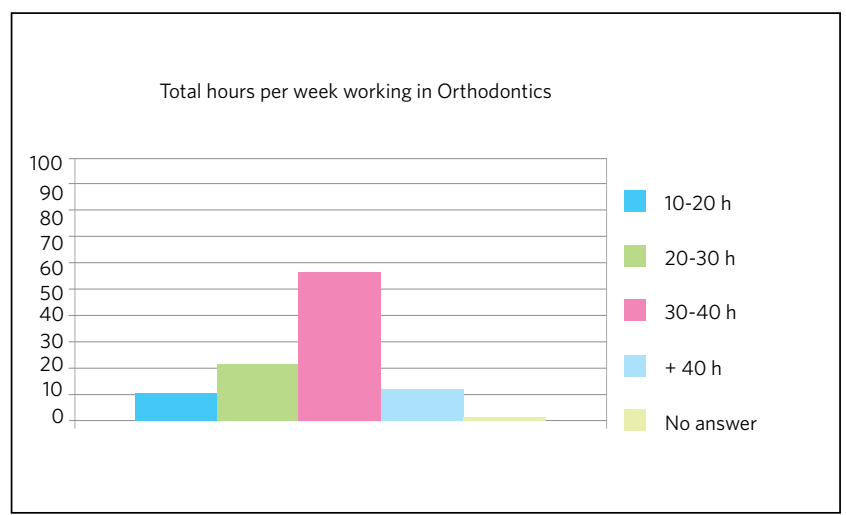

Figure 4 - Total hours per week working in Orthodontics.

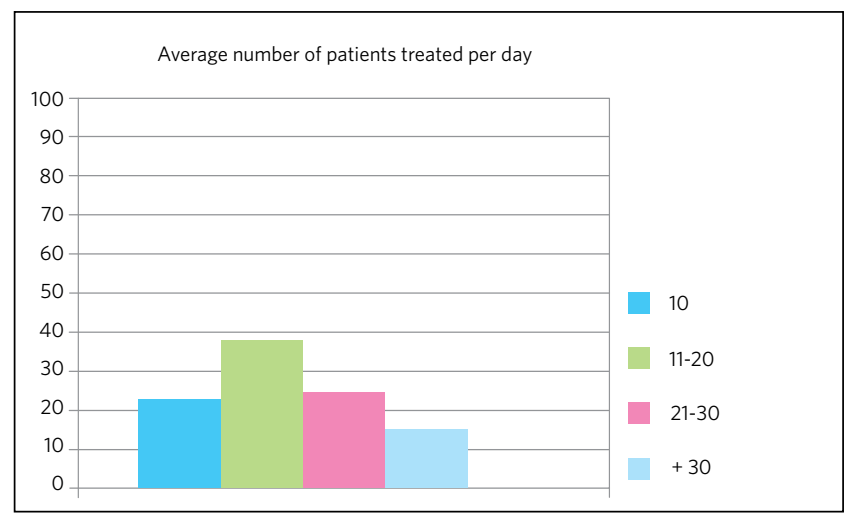

Figure 6 - Distribution of the sample according to the average number of patients treated per day.

five patients $22.4 \%$ and from 11 to 15 patients $17.8 \%$ of the sample.

In respect to patients who needed orthognatic surgery, the demand for treatment was three to five patients a year in $35.7 \%$ of the sample; 1 to 2 patients 


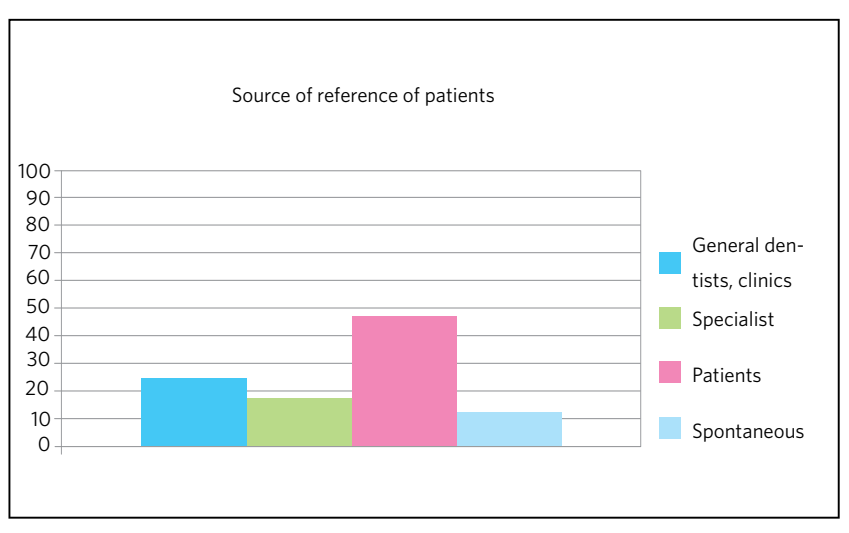

Figure 7 - Distribution of the sample according to the source of reference.

in $33.6 \%$ of the sample and more than 10 patients per year in $9.1 \%$ of the sample.

" Radiographic records: $100 \%$ of the orthodontists requested radiographic records at some phase of the treatment; $98.8 \%$ requested it at the beginning of treatment, $70.5 \%$ requested it at an intermediate phase and $80.01 \%$ requested the records at the end of treatment.

Regarding the type of records requested, the examination were distributed as follows: cephalometric radiograph, 97.1\%; panoramic radiograph, 96.3\%; dental casts, 94.6\%; photographs, 93.4\%; periapical radiographs of incisors, $70.01 \%$; periapical radiographs of all teeth, $42.7 \%$; slides, $22.8 \%$.

In relation to cephalometric analyses used for diagnostics, the most used by the orthodontists from Minas Gerais was the USP, with $48.1 \%$ of preference. Afterward came: Steiner-Tweed cephalometrics, with $32.8 \%$; Ricketts, with $27.8 \%$; Profis, with $19.5 \%$; and finally, Sassouni with $14.9 \%$ (Fig 8).

" Orthodontic techniques and appliances used: The Edgewise Straight-Wire orthodontic technique was shown to be the most used by the orthodontists in Minas Gerais, with the preference of $73.4 \%$ of the practitioners. $35.3 \%$ used the Standard Edgewise technique and $13.7 \%$ practiced Rickettsbioprogressive technique (Fig 9).

The size of the slot of the brackets most used in Minas Gerais is 0.022 -in, with $80.9 \%$ preference, and the 0.018 -in with $16.2 \%$. The other $2.9 \%$ of the participants did not respond.

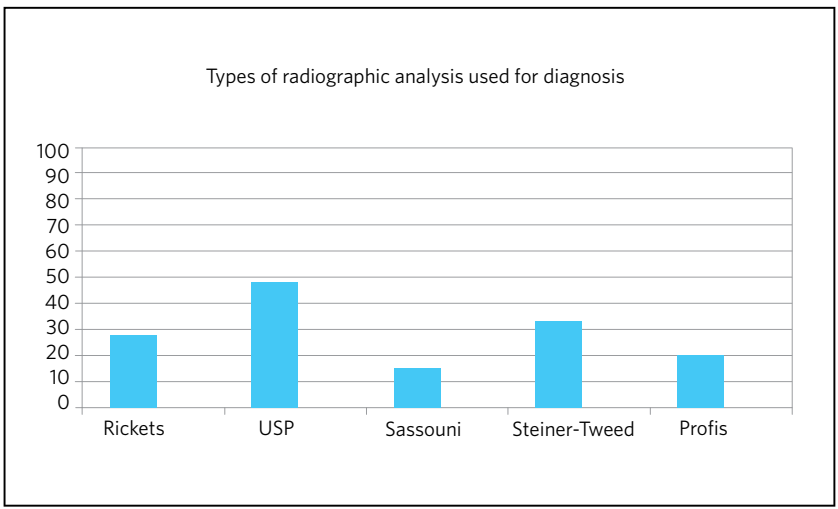

Figure 8 - Distribution of the sample according to the procedures adopted by orthodontists and type of radiographic analysis used for diagnosis.

It is shown that $54.8 \%$ of the practitioners perform Orthopedics, and the most used appliances were: Bionator $(65.6 \%)$, Planas (27.0\%), Bimler (22.8\%) and Frankel (10.0\%) (Fig 10).

In regard to extraction, $63.9 \%$ of the practitioners declared that they use extractions for orthodontic purposes only when necessary; the other $32.8 \%$ preferred to avoid extraction.

» Legal aspects of services provided: $80.1 \%$ of the practitioners fill out records with the clinical history of the patient; $88 \%$ formalize treatment plan in written document; $83.4 \%$ requested the patient's signature on a document before initiating treatment; and $73 \%$ prepare a service contract form before initiation orthodontic treatment, with $40 \%$ of these contracts being revised by a lawyer.

" Use of computers in the office: $75 \%$ of the participants declared the use of computers in the office.

» Use of biosafety equipment in the office: The use of biosafety equipment was distributed as follows: 96.25\% of the practitioners used gloves; $95.8 \%$ masks; $77.6 \%$, safety glasses; $44 \%$, caps; and $80 \%$, lab coats (Fig 11). The percentage of practitioners who used all these types of biosafety items was $37.76 \%$.

» Degree of professional development, regulation institutions, and outlook for the future of the profession: $38.6 \%$ of the practitioners attend conferences once a year, $22.4 \%$ twice a year and $35.3 \%$ attend more than two conferences annually.

Of those interviewed, $55.2 \%$ consider themselves updated, $41.5 \%$ very updated, and $0.4 \%$ not updated. 


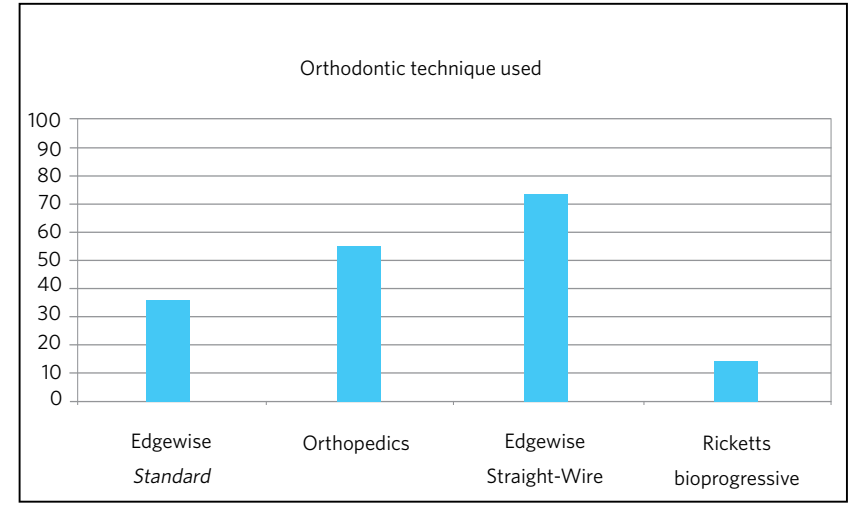

Figure 9 - Distribution of the sample according to the orthodontic technique used.

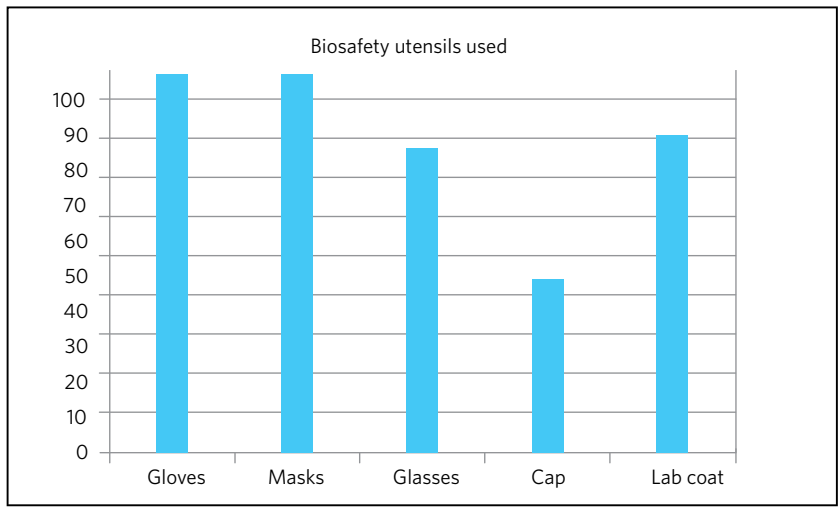

Figure 11 - Distribution of the sample according to the use of biosafety utensils.

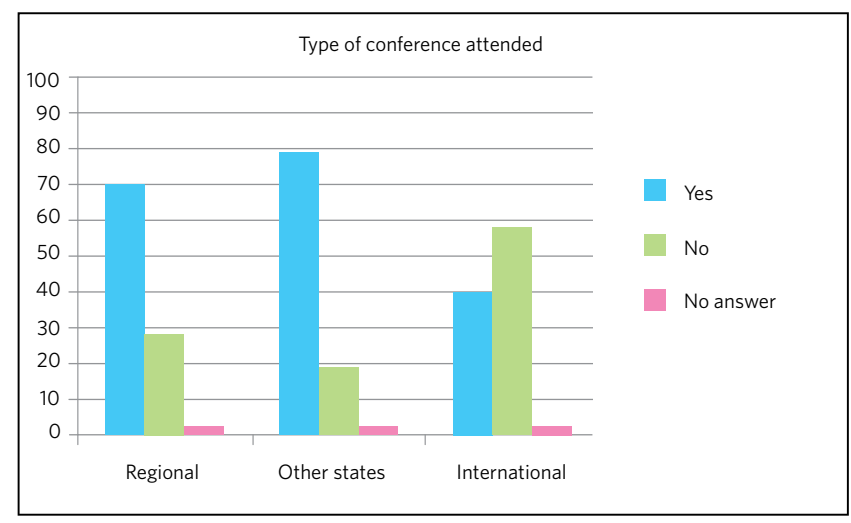

Figure 13 - Distribution of the sample according to the type of conference attended.

Among those who consider themselves updated, $42.15 \%$ attend conferences in other states (Fig 12). The orthodontists indicated that the conferences they attend in other states represent $79.3 \%$; regional conferences $69.7 \%$, and international conferences $40.2 \%$ (Fig 13 ).

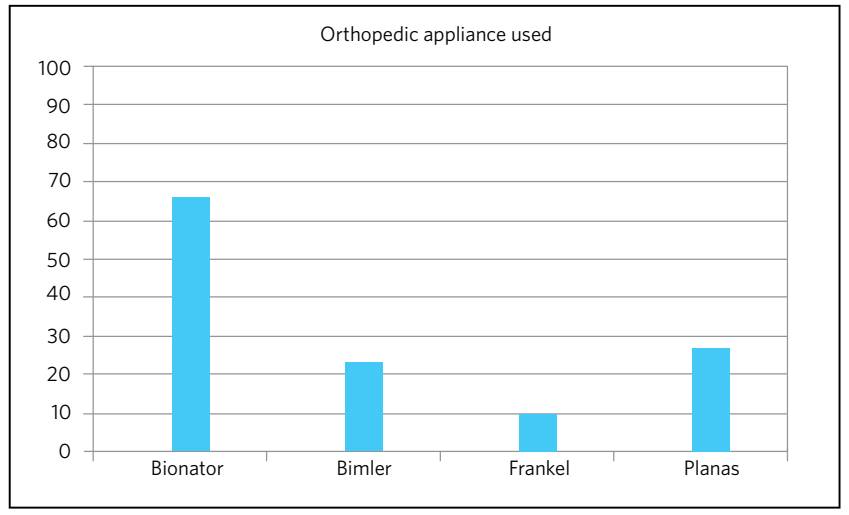

Figure 10 - Distribution of the sample according to the orthopedic appliance used.

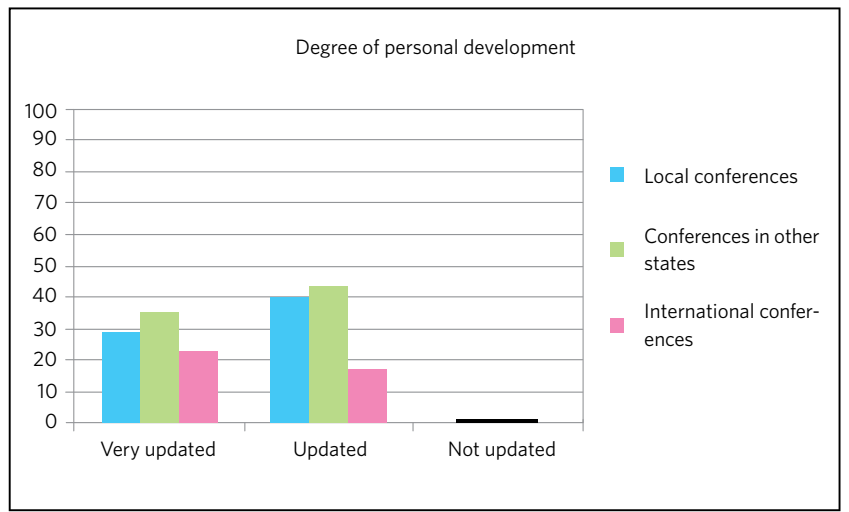

Figure 12 - Distribution of the sample according to the degree of personal development and conferences attendance.

Regarding participation in some kind of professional association, $80.1 \%$ participate in a regional group; $34 \%$ in a national group; $30.3 \%$ participated in groups in other states, and $15.7 \%$ had correlation to an international group. The specialists who did not take part in any professional group totaled 7.1\%.

Among the practitioners, $45 \%$ revealed a positive outlook on the future of the specialty; $22.6 \%$ showed a neutral outlook, and $28.6 \%$ a negative outlook.

The suggestions provided by the specialists to improve the regional professional group are listed below:

- Create a seal of quality, such as that used by plastic surgeons.

- Develop improvement campaigns for the specialty and the practitioner, as well as increasing public awareness and enlightenment in respect the importance of orthodontics.

- Supervise professional practice.

- Motivate greater participation of orthodontists in professional groups, strengthening and turning them into an active voice in society. 
- Create instruments that can prohibit non-regulated courses, in cooperation with the Ministry of Education and Culture (MEC) and the Federal Council of Dentistry (CFO).

\section{DISCUSSION}

On March 2005, the Regional Council of Dentistry of the State of Minas Gerais (CRO-MG) listed 722 orthodontists, a number that represents $9.81 \%$ of the specialists in Brazil. By the same date, Brazil had 6,428 specialists in Orthodontics and Facial Orthopedics.

Our sample, represented by 241 questionnaires, corresponds to $33.3 \%$ of the total number of practitioners in the state of Minas Gerais. In 1992, 1,597 orthodontists were registered with the Federal Council of Dentistry (CFO). ${ }^{14}$ In 1995, 2,008 specialists in orthodontics were duly registered with the CFO. ${ }^{13}$ In 2001, this number increased to $3,831 .{ }^{10} \mathrm{~A}$ national survey showed that the orthodontists represented $16.4 \%$ of the dentists registered with the Federal Council of Dentistry in $1993 .^{2}$

» Gender: We could note the increase of women participation in the labor market, corresponding to a proportion of one woman $(28.2 \%)$ for every three male orthodontists (71.8\%). In 2002, a national survey showed that the number of Brazilian female dentists $(57.5 \%)$ had already exceeded the number of Brazilian male dentists (42.5\%). ${ }^{2}$

"Age: In regard to the age of the specialist practitioners in orthodontics, the results showed that in Minas Gerais the average age was 39 years, with the minimum age of 27 years and the maximum of 82 . In this same period, the majority (29.5\%) of Brazilian dentists were between 26 and 39 years of age. ${ }^{2}$

" Marital status: The number of married practitioners represented $75.9 \%$ of the sample; $13.3 \%$ are single. The percentage of single clinicians interviewed in 2002 was much greater (41\%) when compared to married ones $(54.2 \%){ }^{2}$

» Demographic profile: When compared to dentists throughout Brazil, who in their majority (83.9\%) practice only in the city where they live, ${ }^{2}$ the percentages are inverted for orthodontists in Minas Gerais, whose work takes place away from their residence $(88.37 \%)$.
" Academic degree: $91 \%$ had full specialist title; $24 \%$ had a master's degree and $4.6 \% \mathrm{PhD} .42 .7 \%$ of Brazilian dentists have not completed post-graduation courses mainly due to the lack of financial resources (46.6\%) and lack of time (19.5\%). Those who have completed post-graduate education represented $42 \%$ of specialists and a minority of masters (2.6\%) and doctors $(1.6 \%){ }^{2}$

» Profession: The majority (96.7\%) of orthodontists worked for themselves with no formal link with companies, which corresponded to the Brazilian general dentists situation $(89.6 \%){ }^{2}$ It was seen that $56.4 \%$ worked an average of 30 to 40 hours per week (Fig 4). The same proportion of working hours was verified in relation to dentists throughout the country (54.6\%). ${ }^{2}$

" Patients: It is assumed that the best age for treatment of malocclusion is during the growth phase ranging from 6 to 14 years. In the present study, however, it is seen that the demand for treatment of children up to 10 years of age is low $(19.82 \%)$ and is similar to that of adult patients over 30 years of age (18.98\%).

The patients in $46.79 \%$ of the cases searched for treatment without being referred by any professional, and $24.26 \%$ were introduced by dental clinicians. The present finding confirms a previous study that showed that: the greatest source of coming clients is the patient's own initiative (89.2\%). ${ }^{10}$

The demand for treatment from patients with TMD was distributed as follows: $29.5 \%$ of the sample treated more than 15 patients per year; $26.6 \% 6$ and 10 patients; $22.4 \%$ up to 5 patients; and $17.8 \% 11$ and 15 patients.

$\mathrm{TMD}^{14}$ was found in $74.49 \%$ of the patients. The necessity for a more careful examination of the signs and symptoms of temporomandibular disorder (TMD) - before beginning orthodontic treatment - has already been emphasized in a study involving 168 adolescents, which correlated symptoms of facial pain and discomfort in female patients, mainly in post-orthodontic treatment. ${ }^{9}$

In another study, the prevalence of TMD was observed in 201 pre-orthodontic patients, which led the researchers to the conclusion that, in a great number of patients, there is a pre-existing subclinical TMD condition, which can be exacerbated by orthodontic treatment. ${ }^{11}$ 
It is opportune also to mention that orthodontists, who are responsible for the maintenance of balanced functional occlusion, many times neglected the integrity of $\mathrm{TMA}^{5}$ and the mandibular musculature of pre-orthodontic adolescents with TMD symptoms. ${ }^{12}$

In respect to patients needing orthognatic surgery, the demand was divided as follows: $35.7 \%$ of the sample treated from 3 to 5 patients; $33.6 \%$ from 1 to 2 patients; and $9.1 \%$ treated more than 10 patients. The literature cited the prevalence of $63.37 \% .^{14}$ of this kind of patient. Consequently, it is necessary for the investigated orthodontists to work in an interdisciplinary manner with the oral and maxillofacial surgery specialty.

" Radiographic records: $100 \%$ of the orthodontists requested radiographic records at some phase of treatment, given the importance of these complementary exams, not only for diagnosis, but also for legal reasons. Contrary to these findings, we observed that intermediate and final records were not being requested by $82.8 \%$ of orthodontists. ${ }^{10}$

" Orthodontic techniques and appliances used: The orthodontic technique preferred by the orthodontists in Minas Gerais is the Edgewise Straight-Wire, with $73.4 \%$ of use. There is a significant group that use the Standard Edgewise technique (35.3\%) and a smaller group (13.7\%) that practices Ricketts-bioprogressive.

Several factors influenced the use of new orthodontic practices such as the Straight-Wire technique. These factors are: productivity, or in other words, less clinical time that the patient spends in the orthodontist's chair, and the desire of every practitioner to simplify treatment methods, while at the same time seeking for excellence and stability.

" Legal aspects of services provided: Due to the possibility of legal demands regarding dental procedures, it became important to emphasize certain preventive actions on the legalization of the service provided to the patients. ${ }^{8}$ This study found concern among the participating orthodontists in relation to the legal aspects: $80.1 \%$ affirmed that they fill out clinical forms; $88 \%$ formalize treatment plan in written document; $73 \%$ required signed contract prior to beginning of the treatment, with $40 \%$ of these contracts being reviewed by a lawyer.
» Use of computers in the office: $75 \%$ of participants disclosed that they use a computer in the office. Comparatively, $43.3 \%$ of Brazilian dentists revealed to use computer. ${ }^{2}$

" Use of biosafety equipment in the office: The percentage of practitioners who use all types of biosafety items is still low (37.76\%) and needs emphasis. In order to prevent occurrences of contamination in the team and to protect the patients from possible infections, all patients should be considered as potential vectors of some kind of disease.

»Professional associations and the outlook for the future of the profession: $80.1 \%$ of the practitioners participated in some regional group; $34 \%$ participated in a national group; $30.3 \%$ participated in groups in other states; and $15.7 \%$ in international groups. It was noted that $7.1 \%$ of the specialists did not participate in any professional group. Among general clinicians, we found that $57.7 \%$ participated in some professional group such as Associations (94.4\%). The degree of satisfaction in relation to this type of group was high (22.6\% excellent and $47.7 \%$ good). ${ }^{2}$

According to the findings we noted that: $45 \%$ of the practitioners have a positive outlook for the future of the specialty; $22.6 \%$ were neutral while $28.6 \%$ provided negative perspectives.

Among Brazilian general dentists, the situation was a little better, with $69.1 \%$ of the interviewees declaring that they would choose the same profession if hypothetically needed $69.5 \%$ reporting optimism about the future of dentistry. ${ }^{2}$ In contrast to these data, other authors indicated an high percentage (66.9\%) of orthodontists who would not encourage their children to study dentistry at present. ${ }^{10}$

Seeking a more promising future for the profession, the specialists who participated in the study made several requests to the regulative institutions, as follows: reduction of the number of courses and orthodontists; opening new specialization courses, bringing greater possibilities of financial benefits for practitioners, as well as improving their performance. enhance financial income for the specialist in orthodontics and enhance social recognition.

\section{CONCLUSION}

This study allowed us to obtain information to define the profile of practitioners of Orthodontics in the state 
of Minas Gerais, focusing at professional individuality, patients, education and the techniques used. In relation to the target public, we can conclude that it is comprised, mainly, of adolescents (33.75\%) and young adults (27.45\%). Patients come to the offices of orthodontists predominantly by own initiative (46.79\%). Among the most relevant information collected, we can cite the lack of use of some individual protection equipment, with only $37.76 \%$ using all the items for biosafety.

Final records has been requested with less frequency than initial ones, which can be considered a negligence in orthodontic treatment. In regard to future perspectives of the profession, optimistic orthodontists did not exceed half (45\%) of those interviewed.

\section{REFERENCES}

1. Almeida MR, Vieira GM, Guimarães Junior $\mathrm{CH}$, Neto $\mathrm{MA}$, Nanda R. Emprego racional da Biomecânica em Ortodontia: "arcos inteligentes". Rev Dental Press Ortodon Ortop Facial. 2006:11(1):122-56.

2. Conselho Federal de Odontologia (CFO). Perfil do CirurgiãoDentista no Brasil. Relatório de pesquisa do Instituto Brasileiro de Estudos e Pesquisas Socioeconômicas [internet]. Londrina: INBRAPE; 2003. [cited 2008 Oct 16]. Available from: http://www.cfo. org.br/download/pdf/perfil_CD.pdf.

3. Gottlieb EL. Population. Orthodontics Economics. J Clin Orthod. 1980a Aug;14(8):572-4.

4. Gottlieb EL. Number of Orthodontists. Orthodontics Economics. J Clin Orthod. 1980b Aug;14(8):572-4.

5. Gottlieb EL. Are you ready for a computer? J Clin Orthod. 1981 Jan;15(1):52-61.

6. Gottlieb EL, Nelson AH, Vogels DS. JCO orthodontic practice study. Part 1. Trends. J Clin Orthod 1985;19:799-806.

7. Gottlieb EL, Nelson AH, Vogels DS. Study of orthodontic diagnosis and treatment procedures. Part I: results and trends. J Clin Orthod. $1991 ; 25: 145-56$
8. Koubik R, Feres MAL. Aspectos legais da Ortodontia. Ortodontia. 1995;28(2):64-70.

9. Loft GH, Reynolds JM, Zwemer JD, Thompson WO, Dushku J. The occurrence of craniomandibular symptoms in healthy young adults with and without prior orthodontic treatment. Am J Orthod Dentofacial Orthop. 1989 Sep;96(3):264-5.

10. Morgenstern AP, Feres MAL, Petrelli E. Caminhos e descaminhos da Ortodontia no Brasil. Rev Dental Press Ortodon Ortop Facial. 2004;9(6):109-21.

11. Morrant DG, Taylor GS. The prevalence of temporomandibular disorder in patients referred for orthodontic assessment. $\mathrm{Br} \mathrm{J}$ Orthod. 1996 Aug;23(3):261-5.

12. Perry HT Jr. Adolescent temporomandibular dysfunction. Am J Orthod. 1973 May;63(5):517-25.

13. Pissette AP. II Estudo sobre a prática ortodôntica no Brasil - 1995. Ortodontia. 1997:30(3):7- 15.

14. Queiroz Júnior G, Feres MAL. Estudo sobre a prática ortodôntica no Brasil. Ortodontia. 1994;27(3):67-77.

15. Rudolph DJ, Sinclair PM. Orthodontic graduate education survey 1983 1994. Am J Orthod Dentofacial Orthop. 1997 Oct;112(4):418-24. 